\title{
AMBIENTE ECOLOGICAMENTE EQUILIBRADO, RESPONSABILIDADE PENAL DA PESSOA JURÍDICA E A REGRA DA DUPLA IMPUTAÇÃO MATERIAL: a Jurisprudência do STJ em Descompasso com a nova Hermenêutica do STF
}

Ecologically balanced environment, criminal liability of the legal entity, and the rule of double material accusation: jurisprudence of the STJ out of keeping with the hermeneutic of the STF

\author{
Rodrigo José Leal \\ Universidade Regional de Blumenau - Furb - Blumenau - Santa Catarina - Brasil
}

RESUMO: Este estudo tem como foco a controvertida questão da responsabilidade criminal da pessoa jurídica - RPPJ, em especial, o problema relacionado à imputação material das infrações penais ambientais cometidas pelo ente jurídico. Como é sabido, o art. $3^{\circ}$, da Lei 9.605/1998 ou Lei de Crimes Ambientais - LCA, responsabiliza a pessoa jurídica nos casos em que a infração ambiental seja cometida por decisão de seu representante legal ou contratual, que tenha atuado no interesse e por conta de uma decisão societária. Assim, a norma reconhece que a infração penal imputada ao ente coletivo está conectada a uma ação criminosa praticada por uma pessoa física. A doutrina e a jurisprudência convergiram no entendimento de que não poderia haver responsabilidade criminal da pessoa jurídica, isoladamente, mas somente quando em concurso com a pessoa física que tenha realizado a conduta descrita na norma incriminadora da LCA. Ocorreria aí uma hipótese de concurso necessário de agentes ou a regra da dupla imputação. No entanto, é preciso reconhecer que $0 \S 3^{\circ}$ do art. 225, da CRFB, não estabelece qualquer condição ao se referir à RPPJ. Por isso, a hermenêutica doutrinária e jurisprudencial elaborada sobre o alcance do dispositivo legal em exame, que predominou sem divergências, poderá mudar completamente, com a recente decisão do STF, que decidiu respaldar ação penal unicamente contra Petrobras, depois que seu presidente e um dos dirigentes da empresa foram excluídos da ação penal. ${ }^{1}$ É o que será examinado neste artigo.

Palavras Chave: Crime. Meio Ambiente. Pena. Pessoa jurídica.EquilíbrioEcológico.

ABSTRACT: The focus of this study is the controversial question of criminal liability of the legal entity - RPPJ, in particular, the problem related to the material accusation of criminal infractions against the environment committed by the legal entity. As is known, article 3 of Law 9,605/1998, or the Law of Environmental Crimes (Lei de Crimes Ambientais - LCA), holds the legal entity

\footnotetext{
${ }^{1}$ RE 548181/PR, j. em 06.08.2013 e publicado somente em 30.10.2014.
}

Revista do Direitoda UNISC, Santa Cruz do Sul, v.1, n. 45, p. 61-88, jan. - abri. 2015. 
liable in cases where the environmental infraction is committed by the decision of its legal or contractual representative, who has acted in the interest and on behalf of a corporate decision. Thus, the rule recognizes that the criminal infraction imputed to the collective entity is related to a criminal act committed by an individual. The doctrine and jurisprudence converge in the understanding that there can be no criminal responsibility of the legal entity in isolation, but only when occurring simultaneously with the individual who committed the act described in the incriminating rule of the LCA. Thus, a hypothesis of necessary simultaneity of agents, or the rule of double accusation, could occur. However, it is necessary to recognize that $\S 3$ of art. 225 of the CRFB does not establish any condition that refers to the RPPJ. For this, the doctrinal and jurisprudential hermeneutic elaborated within the scope of the legal provision in question, which prevails without divergences, could change completely with the recent decision of the STF, which decided to support penal action solely against Petrobras, after its president, and one of the directors of the company were excluded from the penal action. ${ }^{[1]}$ This is what will be examined in this article.

KEYWORDS: Crime. Criminal Penalty. Ecological Balance. Environment. Legal Entity.

\section{CONSIDERAÇÕES INICIAIS}

Não se pode negar a relevância políticojurídica da Constituição da República Federativa do Brasil - CRFB/88. Em todos os sentidos, seu texto, comprometido com a construção de um Estado Democrático de Direito e de bem estar social, fundado entre outros valores na dignidade da pessoa humana, na cidadania e no pluralismo político, com o objetivo de construir uma sociedade livre, justa e solidária, constitui um importante instrumento políticojurídico formal na história do povo brasileiro.

Em sintonia com o pensamento ambientalista que se consolidou durante a segunda metade do século 20 e com as diretivas e princípios aprovados em congressos e conferências mundiais promovidos pela ONU, a CRFB/88 abriu importante espaço normativo para firmar o indispensável compromisso com o controle e a preservação do ambiente saudável e equilibrado. Por isso, a doutrina tem considerado o capítulo de nossa Carta Magna, que trata do meio ambiente ecologicamente equilibrado, como um dos mais importantes $e$

\footnotetext{
${ }^{[1]}$ RE 548181/PR, judged on 06.08.2013 and published on 30.10.2014only.
}

Revista do Direitoda UNISC, Santa Cruz do Sul, v.1, n. 45, p. 61-88, jan. - abri. 2015. 
avançados. É a opinião de José Afonso da Silva. Fazendo menção ao art. 225, salienta 0 fato de a Constituição ter proclamado o meio ambiente ecologicamente equilibrado como direito de todos, "para lhe dar a natureza de bem de uso comum do povo e essencial à sadia qualidade de vida" (SILVA, 2005, p. 845).

Assim sendo, cumprindo o mandamento constitucional prescrito no referido $\S 3^{\circ}$, do art. 225, o Congresso Nacional aprovou a Lei 9.605/98, Lei de Crimes Ambientais, doravante denominada também de LCA. Com suas normas de aplicação geral e de definição dos crimes ambientais, esta Lei representou a corporificação de, praticamente, todo o Direito Penal Ambiental brasileiro. Dentre suas inúmeras disposições, a mais inovadora e, por isso mesmo, a que causou maior divergência na doutrina e, até certo momento, na jurisprudência, pode ser destacada a norma contida no art. $3^{\circ}$, que inseriu em nosso sistema de controle punitivo, a responsabilidade penal da pessoa jurídica, doravante denominada também de RPPJ. O dispositivo tem a seguinte redação:

As pessoas jurídicas serão responsabilizadas administrativa, civil e
penalmente conforme o disposto nesta Lei, nos casos em que a
infração seja cometida por decisão de seu representante legal ou
contratual, ou de seu órgão colegiado, no interesse ou benefício da
sua entidade. Parágrafo único. A responsabilidade das pessoas
jurídicas não exclui a das pessoas físicas, autoras, co-autoras ou
partícipes do mesmo fato.

A promulgação da LCA haveria de suscitar intensos comentários e acesas divergências de parte da doutrina penal. Muitos penalistas levantaram críticas severas, chegando a se manifestar - mesmo diante da vigência de lei expressa - pela inconstitucionalidade da norma contida no art. 3ํㅜ que introduziu a capacidade penal da pessoa jurídica, no sistema jurídico brasileiro.

Não se pode esquecer que, desde a edição do Código Criminal de 1830, - Direito Penal brasileiro, respaldado pelo pensamento doutrinário predominante, havia se mantido firme ao lado da doutrina societas delinquerenon potest. Por isso, era e continua sendo compreensível, a reação de muitos penalistas contrária à conveniência política e à validade técnicojurídica do art. 3ํㅡㄹ da Lei 9.605/98. Em síntese, os argumentos alegam que a norma infringe os princípios constitucionais da culpabilidade e da

Revista do Direitoda UNISC, Santa Cruz do Sul, v.1, n. 45, p. 61-88, jan. - abri. 2015. 
pessoalidade da pena(LUISI, 2010), ${ }^{2}$ que é desnecessária e que constituiu uma "afronta à tradição" do direito brasileiro (REALE JÚNIOR, 1999).

Severo crítico da LCA, Luiz Regis Prado sustenta que a norma contida no art. $3^{\circ}$ não respeitou os princípios da personalidade das penas, da culpabilidade e da intervenção mínima, além de ser um "exemplo claro de responsabilidade penal objetiva" (PRADO, 2005, p. $175-6$ e 180). ${ }^{3}$ Grandeparcela da atual doutrina penal brasileira ainda se mostra refratária à doutrina societas delinquere non potest e, em consequência, não admite a validade da norma contida no art. $3^{\circ}$, da LCA (SILVA,2008, p. 258-9)

No entanto, boa parte da doutrina recepcionou positivamente a promulgação LCA, especialmente, no que concerne à inserção da regra da capacidade penal da pessoa jurídica, no sistema penal brasileiro. Em síntese, entendem esses autores que a existência de um comando normativo em nível constitucional é fonte de legitimidade jurídica suficiente para imprimir validade à norma infraconstitucional.

Nessa linha de pensamento, Lúcio Ronaldo Ribeiro (1998, p. 88)mostrou-se receptivo à ideia de se punir criminalmente a pessoa jurídica, ressaltando que a inovadora regra contida no art. $3^{\circ}$, da LCA, "deve ser entendida à luz de uma responsabilidade social". ${ }^{4}$ Reconhecendo que o Direito Penal deve estar atento às mutações sociais, políticas, culturais e econômicas e, por isso, "adotar institutos e conceitos jurídicos pertinentes à realidade imperante", Manoel Carpena Amorim (2000, p. 37) também defende a validade da norma que introduziu a regra da RPPJ no ordenamento jurídico brasileiro.

\footnotetext{
${ }^{2}$ Nesta obra, estão reunidos diversos artigos cujos autores posicionam-se contrariamente à conveniência políticojurídica de se incriminar a pessoa jurídica ou de autores que, embora admitam tal responsabilidade, entendem que 0 art. $3^{\circ}$, da LCA contrariou princípios penais como o da culpabilidade, da personalidade da pena ou da intervenção mínima.

${ }^{3}$ Adverte, ainda, referido autor, em estudo publicado em outra fonte "que o legislador de 1998, de forma simplista, nada mais fez do que enunciar a responsabilidade penal da pessoa jurídica, cominando-lhe penas, sem lograr, contudo, instituí-la. Isto significa não ser elapassível de aplicação concreta". In: PRADO, Luiz Regis. Crime ambiental: responsabilidade penal da pessoa jurídica? Boletim IBCCrim - Publicação oficial do Instituto Brasileiro de Ciências Criminais, ed. Especial, n. 65, p. 2-3, São Paulo, abril/1998, p. 3.

${ }^{4} J o s e ́$ Carlos Rodrigues de Souza ressalta que a conduta antissocial praticada por empresas degradadoras do meio ambiente necessitava de maior repressão, como no caso da repressão criminal. In: SOUZA, José Carlos Rodrigues de. Responsabilidade penal da pessoa jurídica e sua justificativa social. Revista de Direito Ambiental - Publicação oficial do Instituto "O Direito por um Planeta Verde", ano 3, n.9, p. 137-144, São Paulo, RT, jan.-mar. 1998, p. 140.
}

Revista do Direitoda UNISC, Santa Cruz do Sul, v.1, n. 45, p. 61-88, jan. - abri. 2015. 
Considera que a LCA constitui um "marco fundamental para acabar, de vez, com qualquer discussão sobre a existência ou não de tal responsabilidade". 5

Apesar da ainda persistente divergência verificada na doutrina brasileira, cremos que a Lei 9.605/98 apoiou-se em norma constitucional para positivar, de forma expressa, a responsabilidade criminal da pessoa jurídica. Entendemos que a existência de um comando normativo em nível constitucional é fonte de legitimidade jurídica suficiente para imprimir validade a essa norma infraconstitucional. Num exercício de hermenêutica conforme a Constituição, chega-se à conclusão de que prevalece uma vontade constitucional originária, no sentido de se responsabilizar criminalmente os entes coletivos, como forma de se garantir um ambiente ecologicamente saudável e equilibrado. Dessa forma, ao aprovar a Lei dos Crimes Ambientais para instituir a capacidade penal da pessoa jurídica, o legislador brasileiro nada mais fez do que uma opção de Política Criminal, lastreada na diretiva já consagrada em nossa Carta Magna.

Além do mais, a superação da doutrina societas delinquere non potest manifesta-se como uma tendência contemporânea inevitável, por atender às recomendações contidas nas diretivas e atos normativos supranacionais, aos insistentes apelos do movimento ambientalista mundial e ao novo pensamento da Dogmática Penal.

Portanto, com a promulgação da CRFB/88 e da norma contida no $\S 3^{\circ}$, do art. 225, o sistema jurídico brasileiro, apesar da divergência doutrinária sobre a questão, foi armado de um sólido alicerce para suportar a positivação, em nível infraconstitucional, da RPPJ. ${ }^{6}$ É o que veio a ser concretizado 10 anos após, com a promulgação da Lei 9.605/98.

\footnotetext{
${ }^{5}$ Carlos Alberto de Salles também tratou da matéria e entende que "A possibilidade de responsabilização da pessoa jurídica, não obstante algumas falhas e dificuldades, está claramente dada por nosso sistema legal, inclusive por meio de permissivo constitucional". In: SALLES, Carlos Alberto de. Responsabilidade penal da pessoa jurídica e a proteção ao meio ambiente: finalidade e aplicação. Revista Brasileira de Ciências Criminais - Publicação oficial do Instituto Brasileiro de Ciências Criminais, ano 9, n. 36, p. 51-67, São Paulo, RT, out.dez. 2001, p.66.

${ }^{6}$ Há três posições na doutrina brasileira acerca da interpretação do $\S 3^{\circ}$, do artigo 225 , da CRFB/88: a) admitiu a RPPJ; b) admitiu a RPPJ, mas é preciso uma revisão dos princípios constitucionais penais para poder implementar o novo instituto no Brasil; c) não houve previsão no $\S 3^{\circ}$, do artigo 225, da CRFB/88, da RPPJ. In:PRADO, Alessandra Rapassi M. Proteção penal do meio ambiente: fundamentos. São Paulo: Atlas, 2000, p. 133.
}

Revista do Direitoda UNISC, Santa Cruz do Sul, v.1, n. 45, p. 61-88, jan. - abri. 2015. 
Diversos foram os questionamentos levantados contra a LCA. O principal consiste em afirmar a falta de capacidade da pessoa jurídica para realizar a ação criminosa, com seu indispensável elemento subjetivo. Portanto, não estaria ela dotada do requisito da imputabilidade sobre o qual se assenta um dos elementos do crime, que é a culpabilidade penal. Realmente, a questão da imputação material para se atribuir responsabilidade penal a uma empresa, pela prática de um crime ambiental, tem sido uma questão geradora de sérias e calorosas divergências, seja na doutrina, seja na jurisprudência.

Sem adentrar na polêmica seara do conceito de ação, pode-se dizer que esta tem seu significado penal vinculado a um comportamento direcionado pela vontade humana. É evidente que esse modo de se comportar tem relevância jurídica, seja quando manifestado de forma comissiva ou de forma omissiva.

Assim sendo, se o crime é o resultado de um comportamento voluntário, para boa parte da doutrina penal, não poderia a pessoa jurídica ser autora de uma infração penal, já que lhe falta essa capacidade de agir voluntariamente, condição que seria própria das pessoas físicas.

No entanto, os que defendem a validade e conveniência políticojurídica de se incriminar o ente coletivo, salientam que prevalece hoje a teoria da realidade, segundo a qual a pessoa jurídica tem, sim, capacidade de agir e de atuar - por meio de seus órgãos diretivos - no espaço socioeconômico e cultural. E, dessa forma, praticar atividades lesivas ao ambiente, inclusive de natureza criminal. Porém, é preciso não esquecer que a pessoa jurídica só tem condições de agir por intermédio de seus funcionários e dirigentes, sempre que estes, por sua vez, atuarem de conformidade com a "vontade" de seus órgãos administrativos ou decisórios.

Dessa forma, mesmo aceitando-se a teoria da realidade e admitir que a pessoa jurídica tem capacidade de agir no meio econômico, social e cultural, ainda assim não ficaria solucionada - ao menos à luz da teoria do crime ainda vigente - a complexa questão relativa à imputação material para fins de se estabelecer o necessário juízo de censura no caso de crime ambiental praticado pelos entes coletivos.

Revista do Direitoda UNISC, Santa Cruz do Sul, v.1, n. 45, p. 61-88, jan. - abri. 2015. 


\section{A OMISSÃO DA LCA EM CRIAR REGRA EXPRESSA DE} IMPUTAÇÃO MATERIAL À PESSOA JURÍDICA

Aqui, deve ser ressaltado que a LCA foi, lamentavelmente, omissa e simplista, ao inserir uma lacônica regra da capacidade penal da pessoa jurídica e apenas indicar os tipos penais passíveis de serem por ela cometidos, com as respectivas penas em matéria de criminalidade ambiental. Assim, fica evidenciada a forma lacunosa e contraditória com que a lei em exame tratou de tão relevante matéria, pois deixou de editar um conjunto de normas complementares de apoio, de ajuste e de mudanças indispensáveis para que a nova proposta incriminadora dos entes coletivos possa cumprir - com o indispensável grau de efetividade - sua relevante função de defesa do ambiente em face da criminalidade empresarial. ${ }^{7}$ Afinal, a norma contida no art. $3^{\circ}$, da LCA rompeu com uma prática secular fundada no axioma da societas delinquere non poteste todo sistema jurídicopenal estava (e ainda continua) construído e sistematizado para processar e julgar a pessoa física.

A doutrina favorável à validade da norma contida no art. $3^{\circ}$, da LCA, tem procurado construir um conceito de imputação material que seja compatível com a regra da capacidade penal da pessoa jurídica. Afinal, a lei apenas dispõe que a pessoa jurídica será responsabilizada penalmente, pela prática de um crime ambiental, "nos casos em que a infração seja cometida por decisão de seu representante legal ou contratual, ou de seu órgão colegiado, no interesse ou benefício da sua entidade".

Embora o texto legal não seja claro nem explícito, parece evidente que o sentido da norma é de que a pessoa jurídica não pratica diretamente a infração penal contra o ambiente, mas sim por meio de uma pessoa física (seu dirigente ou funcionário em sentido geral), que tenha atuado no interesse e por conta de

\footnotetext{
${ }^{7}$ No caso brasileiro, faltou a edição de uma lei ou de normas no próprio texto da LCA, de ajuste ou de adaptação da regra da capacidade penal da pessoa jurídica aos institutos penais do sistema penal vigente, secularmente construído para a prevenção e repressão das condutas humanas rotuladas como criminosas. Lei dessa natureza foi aprovada na França, com o objetivo de viabilizar a norma prescritiva da capacidade penal da pessoa jurídica (Lei 921336/1992). Sobre a questão ver: ARAÚJO JUNIOR, João Marcello de. Societas delinquerepotest - revisão da legislação comparada e estado atual da doutrina. p. 72-94. In: GOMES, Luiz Flávio (Coord.). Responsabilidade penal da pessoa jurídica e medidas provisórias e direito penal. Coleção temas atuais de direito criminal vol. 2. São Paulo: RT, 1999, p. 82.
}

Revista do Direitoda UNISC, Santa Cruz do Sul, v.1, n. 45, p. 61-88, jan. - abri. 2015. 
uma decisão societária. Ocorre aí uma hipótese de concurso necessário de agentes. Assim, a norma reconhece que a infração penal imputada ao ente coletivo estará sempre conectada a uma ação criminosa praticada por uma pessoa física atuando a serviço do interesse da pessoa jurídica.

Pela dicção literal da norma, a responsabilidade da pessoa jurídica em relação a um crime ambiental terá como elemento subjetivo necessário uma tomada de decisão, pelo colegiado ou órgão diretivo, para a prática do crime. Isto vale para os casos de uma decisão positiva. A ausência de decisão e das providências que se fizerem necessárias por parte do órgão administrador, a fim de evitar, quando possível e previsível, práticas criminosas contra 0 ambiente, equivale também a uma decisão para o crime. ${ }^{8}$

Por outro lado, embora a lei seja omissa, entendemos que o autor direto da conduta delituosa não precisa ser, necessariamente, dirigente ou funcionário da empresa, para que esta seja responsabilizada penalmente. Basta que o agente - pessoa física - tenha atuado em cumprimento de decisão do órgão dirigente e "no interesse ou benefício" da corporação. ${ }^{9}$

É preciso, portanto, encontrar um critério de imputação material e um conceito de culpabilidade que se ajustem à norma contida no art. $3^{\circ}$, da LCA e, assim, justificar a RPPJ pela prática de um crime ambiental. Nesse sentido, dois modelos de teorias foram formulados para fundamentar essa nova forma de responsabilidade penal. ${ }^{10}$

É o que será examinado a seguir, com a necessária brevidade.

\footnotetext{
${ }^{8}$ Aqui entramos no espaço normativo do artigo $2^{\circ}$ da LCA: "Quem, de qualquer forma, concorre para a prática dos crimes previstos nesta Lei, incide nas penas a estes cominadas, na medida da sua culpabilidade, bem como o diretor, o administrador, o membro de conselho e de órgão técnico, o auditor, o gerente, o preposto ou mandatário de pessoa jurídica, que, sabendo da conduta criminosa de outrem, deixar de impedir a sua prática, quando podia agir para evitá-la".

${ }^{9}$ Vale registrar aqui a opinião de Walter ClaudiusRothenburg sobre esse ponto do art. $3^{\circ}$. da LCA: "Eliminou-se indevidamente a hipótese em que a atividade é exercida pela e para a empresa, embora por indivíduos a ela não formalmente vinculados. Em seguida, o dispositivo, correta mas paradoxalmente, amplia o alcance da atuação, que não fica limitada ao objeto social da empresa, bastando ter ocorrido 'no interesse ou benefício' da entidade". In: ROTHENBURG, Walter Claudius. Responsabilidade penal da pessoa jurídica na nova lei de infrações ambientais. Revista de Direito Ambiental - Publicação oficial do Instituto "O Direito por um Planeta Verde", ano 3, n.9, p. 59-66, São Paulo, RT, jan.-mar. 1998, p. 65.

${ }^{10}$ Para uma análise mais detalhada sobre esta questão, consultar: ROSAL, Bernardo del. La delimitación típica de losllamadoshechos de conexiónenelnuevo artículo 31 bis, n. 1, del Código Penal. págs. 41-94, Cuadernos de política criminal, №. 103, 2011, p. 45. Ver, também, SILVA, Fernando Quadros da. Responsabilidade penal da pessoa jurídica: a Lei 9.605, de 13.02.1998 e os princípios constitucionais penais.Revista de Direito Ambiental - Publicação oficial do Instituto "O Direito por um Planeta Verde", ano 5, n.18, p. 163-197, São Paulo, RT, abr.-jun. 2000.
}

Revista do Direitoda UNISC, Santa Cruz do Sul, v.1, n. 45, p. 61-88, jan. - abri. 2015. 


\section{TEORIAS SOBRE A RESPONSABILIDADE CRIMINAL DA PESSOA} JURÍDICA

\subsection{Teorias da Responsabilidade por Transferência ou da} Identificação

Uma proposta teórica de solução do problema é conhecida como teoria da "responsabilidade por transferência" ou por "atribuição" ou, ainda, teoria da “identificação”. Carlos Gómez-JaraDiez (2005, p. 206-7) registra que a denominada responsabilidade vicarial (vicariousliability) começou a ser forjada nos tribunais ingleses a partir do século $X V$, mas seu verdadeiro desenvolvimento ocorreu durante o século $\mathrm{XX}$, com o enfrentamento do Caso Hudson, ocorrido, em 1909. Para o autor, foi aí que teve origem a responsabilidade vicarial, que passou a exigir a intenção na prática dos delitos corporativos. $^{11}$

Para esta doutrina (vicariousliability), a imputação de um crime ao ente coletivo é juridicamente viável quando o autor da infração - sempre uma pessoa física - seja seu representante ou alguém integrante de seu órgão dirigente e sempre que tenha atuado por conta e no interesse da pessoa jurídica. Neste caso, a conduta criminosa praticada pela pessoa física deve ser vista como uma manifestação de vontade do próprio ente coletivo. Assim, se a pessoa jurídica não é dotada de vontade delitiva própria, pode ela, no entanto, atuar por meio de seus dirigentes, que se identificam e concretizam essa vontade ou mente diretiva empresarial ou dos demais entes coletivos. ${ }^{12}$

\footnotetext{
${ }^{11}$ Segundo o autor, em meados do século XIX as empresas eram responsáveis por infrações strictliability, o que significava responsabilidade puramente objetiva: "enlosprimeros casos de responsabilidad penal corporativa no existia imputación subjetiva jurídico-penal de ningún tipo". A expressão inglesa strictliability, segundo José Garcez "pode ser traduzida como responsabilidade estrita ou objetiva ("StrictLiabilityPrinciple"), provém da common law e foi absorvida pelo direito continental, consistindo, em linhas gerais, na responsabilidade independentemente de dolo, culpa, negligência, imprudência ou imperícia". In: GARCEZ, José Maria Rossani. Responsabilidade objetiva ("strict liability"), negligência ("negligence") e negligência dolosa ("gross negligence"). Jus Navigandi, Teresina, ano 12, n. 1617, 5 dez. 2007. Disponível em: <http://jus.com.br/artigos/10732>. Acesso em: 22 fev. 2015.

12 "La responsabilidad por ese hecho delictivo se transfiere a la persona jurídica, en la medida en que se considera que los actos de dichos órganos, en virtud de la relación funcional existente entre éstos y aquélla, son, también, de esta última". In:SILVA SÁNCHEZ, JesúsMaría. La responsabilidad penal de las personas jurídicas y las consecuencias accesorias del

Revista do Direitoda UNISC, Santa Cruz do Sul, v.1, n. 45, p. 61-88, jan. - abri. 2015.
} 
Como ressaltou Bernardo delRosal, para aqueles que defendem esse marco teórico, "el título por elcual se producedichatransferencia de responsabilidad de la persona física a la persona jurídica es laidentificación de lavoluntaddelprimeroconladel segundo, de modo que la persona que actúa no es que actúe para lacorporación, es que es lacorporación."13

A mesma informação é também prestada por Klaus Tiedemann (1999, p. 34-8), assinalando que "desde mediados delsiglo XIX, por razones más bien pragmáticas y de política criminal", a regra da capacidade penal dos entes corporativos foi introduzida no Direito inglês, "en primer lugar para los delitos imprudentes y de omisión" e, posteriormente, para os delitos econômicofinanceiros em geral. Para o autor em referência, este é um modelo viável para países com "ordenamientos jurídicos inspirados en pragmatismo penal que establecela plena responsabilidad penal de lasagrupacionessingranconsideración a los obstáculos dogmáticos". ${ }^{14}$

Por isso, fala-se em responsabilidade por transferência, atribuição ou representação, pois o executor do crime (sempre uma pessoa física) deve ser alguém que, necessariamente, represente o ente coletivo; ou, ainda, em teoria da identificação, pois a conduta do representante ou do órgão dirigente identifica-se com a própria pessoa jurídica. ${ }^{15}$ Assim, conforme escreve

artículo 129 del código penal español. p. 101 e 152. In: GARCíA CAVERO, Percy (Coord.). La responsabilidad penal de las personas jurídicas, órganos y representantes. $1^{a}$. reimp.Mendoza: Cuyo, Nov. 2005, p. 114-5.

${ }^{13}$ Ainda, segundo Bernardo delRosal, a partir de 1995, o direito inglês reformulou as bases da teoria da identificação para adotar o que se denominou de teoria vicária estrita, que admite a responsabilidade criminal da pessoa jurídica, mesmo nos casos em que o crime for praticado por qualquer dos seus funcionários. In: La delimitación típica de losllamadoshechos de conexiónenelnuevo artículo 31 bis, $n$. 1, del Código Penal, p. 46.

${ }^{14}$ Nesse modelo, esclarece o autor, que o órgão dirigente ou o colegiado é visto como sendo o "cérebro" da empresa e suas ações devem ser consideradas como ações da própria empresa (doutrina da identificação). Diante da grande dificuldade de enquadrar a doutrina da "vicariusliability" aos sistemas penais vinculados à teoria subjetiva da culpabilidade, o autor ressalta que existe um outro modelo possível: "desarrollar una nueva dogmática penal para comprender, concategoríasnuevas o adaptadas delderecho penal, lasactividadescriminales de lasagrupaciones". Para ele, "parece muy difícil imputar a una persona, o a una entidad jurídica, la culpa de outra persona", pois "La culpa debe ser lapropia culpa de la persona a condenar". In: TIEDEMANN, Klaus. Responsabilidad penal de personas jurídicas y empresas en el derecho comparado. p.25-45. In: Responsabilidade penal da pessoa jurídica e medidas provisórias e direito penal. Coleção temas atuais de direito criminal vol. 2. São Paulo: RT, 1999, p. 34-8.

${ }^{15}$ Esta é a opinião de AdanNietoMartín, aoescrever que, por este marco teórico,"Se imputa transfiriendo a la empresa todo acto cometido por un agente suyoenelejercicio de suactividadconlaintención de favorecerla". O autor considera que este modelo pode acarretar resultados políticocriminais desastrosos, pela insegurança jurídica que é inerente à sua prática.

Revista do Direitoda UNISC, Santa Cruz do Sul, v.1, n. 45, p. 61-88, jan. - abri. 2015. 
Fernando Quadros, o elemento subjetivo da infração penal transmite-se, por reflexo, à pessoa jurídica beneficiária da ação criminosa (SILVA, 2000, p. 168).

Deve-se assinalar, no entanto, a dificuldade da teoria da atribuição por identificação, por transferência, representação ou empréstimo para sustentar sua adequada aplicação às grandes empresas, que funcionam mediante um sistema organizacional complexo e com diversos níveis de poder decisório.

Por isso, a doutrina tem se esforçado para apresentar um modelo teórico distinto, assentado na ideia de uma forma de responsabilidade própria da pessoa jurídica.

\subsection{Responsabilidade Criminal Própria da Pessoa Jurídica}

O outro modelo de imputação material propõe que a pessoa jurídica atue com responsabilidade criminal própria ou originária e não admite que o processo de transferência de culpabilidade penal seja juridicamente viável. Conforme leciona Bernardo delRosal (2011), os adeptos deste modelo de responsabilidade penal partem do pressuposto fático de que as empresas se constituem em uma realidade em si diversa da dos indivíduos, "con sus propios y distintivos objetivos, supropia y distintiva cultura y supropia y distintiva personalidad, cultura y personalidad que son únicas y nacen de un número identificable de características" ${ }^{16}$ Assim, o juízo de censura em que consiste a culpabilidade, assenta-se na omissão ou deficiência da pessoa jurídica em adotar as medidas necessárias para evitar a prática da ação delituosa.

A imputabilidade ocorreria por meio de um conceito funcional ou puramente normativo, diferente, portanto, do conceito de ação penal como ato de vontade imputável ao indivíduo e a culpabilidade assume uma dimensão

In: NIETO MARTÍN, Adán.La responsabilidad penal de las personas jurídicas: un modelo legislativo. Madrid: lustel, 2008, p. 85 e 126.

${ }_{16}$ Explica que a "culpabilidad por defecto de organizaciónestablecelaresponsabilidad penal de lacorporacióncuando se pueda determinar que, producidoundaño o perjuicio, ésta ha organizado su negocio de forma que las personas y laspropiedadesestánexpuestas a una victimización criminal o a unriesgo de daño no racional". Ou, ainda, "cuando la empresa ha fallado a la hora de establecer sistemas y mecanismos de evitación de riegos criminales, o cuando la supervisión y vigilancia de aquellos a los que ha puesto en situación de cometer un delito o de causar daño es inadecuada, o cuando el ethosde la corporación o su cultura tolera o incentiva la causación de delitos". In:ROSAL, Bernardo del. La delimitación típica de losllamadoshechos de conexiónenelnuevo artículo 31 bis, n. 1, del Código Penal, p. 48.

Revista do Direitoda UNISC, Santa Cruz do Sul, v.1, n. 45, p. 61-88, jan. - abri. 2015. 
social, assentada na ocorrência de uma atividade empresarial deficiente, marcada pela omissão em evitar o cometimento da infração penal.

Escudado em doutrina espanhola, Bruno TanusJob e Meira entende que esse modelo propõe a adoção de uma "culpabilidade de organização", pela qual a pessoa jurídica passa responder por fatos delituosos praticados pela pessoa física, mas "com base na inobservância das medidas de cuidado necessárias para garantir uma correta e legítima atividade empresarial” (MEIRA, 2004, p. 64). ${ }^{17}$

Klaus Tiedemann (1999) defende uma proposta semelhante de responsabilidade penal para o que ele denomina "elderecho de las 'Ordnungswidrigkeiten' alemanas”. Propõe este autor um modelo de culpabilidade que "partiría de un principio de falta (y de culpa) de organización como legitimación de laresponsabilidad de laagrupación”. ${ }^{18}$

JesúsMaría Silva Sánchez ressalta que as construções de uma teoria da culpabilidade por defeito de organização atribuem a culpa pela omissão de um órgão da empresa à própria pessoa jurídica. Assinala que

resulta más que dudoso si laculpabilidad por defecto de organización
es expresión de una culpabilidaden sentido estricto de la persona
jurídica o, por el contrario, una regla de transferencia de
responsabilidad a la persona jurídica por elhechoculpable de las
personas físicas que, enel seno de lamisma, infringenlosdeberes de
organización y vigilancia que recaen sobre ellos.(SILVA SÁNCHEZ,
2005, p. 119 e 127)

Desse modo, percebe-se que o autor espanhol referido destaca a dificuldade em se criar uma culpabilidade própria da pessoa jurídica, pois mais

\footnotetext{
17 O autor faz uma análise das propostas que visam solucionar o problema da imputação material e da culpabilidade da pessoa jurídica e conclui que nenhum dos modelos que trabalha com a concepção de culpabilidade e consequentes penas de caráter criminal aplicáveis à pessoa jurídica mostra-se apto a resolver esse complexo problema. Por isso, defende "um sistema composto por estruturas similares às utilizadas pelo Direito Administrativo sancionador e Direito Penal de uma maneira mais adequada à estrutura empresarial contemporânea sem violar as tradicionais composições técnico-jurídicas desenhadas com base nas condutas praticadas pelas pessoas físicas" (p. 77).

${ }^{18}$ Ainda acerca da Teoria da "culpabilidade por defeito de organização", Mercedes García Arán se manifesta no sentido de que "Lo importante de estos planteaminentos, en mi opinión, es cómo se intenta adecuar las categorías penales a las personas jurídicas antes que substituirlas por otras, porque sólo de esta forma puede estarse hablando realmente de un derecho penal de las personas jurídicas y no de las tradicionales respuestas administrativas aunque bajo otro nombre". In: GARCÍA ARÁN, Mercedes. Algunas consideraciones sobre la responsabilidad penal de las personas jurídicas. p.325-333. In: CEREZO MIR, José et al (Ed.). El nuevo código penal: presupuestos y fundamentos: libro homenaje al professor doctor Don Ángel Torío López. Granada: Comares, 1999, p. 331.
}

Revista do Direitoda UNISC, Santa Cruz do Sul, v.1, n. 45, p. 61-88, jan. - abri. 2015. 
uma vez aqui (defeito de organização) vai se buscar na conduta de outrem a censura penal para poder ser atribuída à empresa. Para Luiz Regis Prado, isso significaria uma "culpabilidade em fato alheio - culpabilidade presumida porque a responsabilidade da pessoa jurídica estaria baseada na imputação do fato culpável de seu órgão ou representante" (PRADO, 2001, p. 107).

\subsection{O Modelo de Responsabilidade Penal Adotado pelo Art. 3ㅜ, da}

LCA

Quanto à LCA, é preciso reconhecer que a redação dada à norma contida no seu art. $3^{\circ}$, peca por falta de clareza e objetividade. Mas, numa interpretação segundo os termos da lei, é possível dizer que o critério ali adotado corresponde ao modelo de responsabilidade penal por atribuição ou de identificação de responsabilidade, pois a lei atribui à pessoa jurídica a responsabilidade criminal decorrente da ação criminosa causada pela pessoa física. Na doutrina brasileira, a corrente largamente majoritária defende esta posição para afirmar que o modelo aqui praticado, por força do art. 3ำ da LCA, é o da dupla imputação ou dupla incriminação.

Segundo LuisRegis Prado (2001), a nossa lei foi influenciada pelo Código Penal francês, que adota o modelo da capacidade penal do ente coletivo por empréstimo ou pelo ricochete, decorrente da responsabilidade penal da pessoa física que tenha atuado em seu nome e por sua conta. ${ }^{19} \mathrm{Na}$ França, escreve Jean Pradel (1998), o códigode seu país fez uma opção pela teoria da dupla incriminação, denominada de "responsabilidade por reflexo ou ricochete". Para o direito francês, esclarece o autor, somente a pessoa física pode atuar com dolo ou culpa, que é o elemento subjetivo de uma infração, segundo a clássica teoria do delito, entendimento que ali prevalece após a Corte de Cassação ter decidido que a pessoa jurídica tem sua responsabilidade penal vinculada à de seus dirigentes ou de seus órgãos de

\footnotetext{
${ }^{19}$ Conforme esclarece Luis Regis Prado, o modelo francês pode ser explicado pelo "mecanismo denominado emprunt de criminalité, feito à pessoa física pela pessoa jurídica". Ou seja, "a responsabilidade penal da pessoa moral está condicionada à prática de um fato punível suscetível de ser reprovado a uma pessoa física". (p. 124).
}

Revista do Direitoda UNISC, Santa Cruz do Sul, v.1, n. 45, p. 61-88, jan. - abri. 2015. 
administração, em relação aos quais (pessoas físicas) é preciso demonstrar que atuaram com o elemento subjetivo do crime. ${ }^{20}$

Assim, a norma brasileira em referência não admite que a pessoa jurídica possa atuar com responsabilidade penal própria no cometimento de uma infração penal ambiental. Sua responsabilidade, em face de um crime ambiental, pressupõe que este seja originariamente imputável à pessoa física atuando na representação, por conta ou no interesse do ente corporativo. ${ }^{21}$

Examinando esta questão, Carlos Alberto de Salles (2001, p. 65)escreve que a opção expressa no caput do art. $3^{\circ}$, da LCA, "não foi a mais condizente com as expectativas", pois ao condicionar a responsabilidade penal do ente corporativo "à existência de uma decisão dos representantes legais ou contratuais", manteve a mesma dificuldade anterior, para se identificar e promover a ação penal contra os dirigentes ou representantes responsáveis pela decisão criminosa contra o ambiente. $O$ autor assinala ainda que, ao exigir que a responsabilização da pessoa jurídica fique sujeita à verificação de uma decisão de seus representantes, na prática judiciária, a norma contida no art. $3^{\circ}$, da LCA, "impõe a necessidade de seus responsáveis figurarem na condição de partícipes ou co-autores, uma vez que, em graus variáveis, deram causa ao delito". 22

Ao abordar esta questão, Lídia Maria Lopes Ribas (2002, p.103) destaca "que a responsabilidade penal da pessoa jurídica não é exclusiva e nem em detrimento de seus dirigentes." Para a autora, trata-se de responsabilidade cumulativa, sendo os sócios, administradores e agentes da pessoa jurídica

\footnotetext{
20. Textualmente, escrevePradel: "Em conclusão, admitimos que o art. 121-2, do CP, globalmente considerado, consagra a tese do reflexo: a pessoa jurídica é responsável por 'ricochete', indiretamente, de sorte que é em relação à pessoa do indivíduo que se torna necessário aferir o dolo e a culpa", p. 53-6.

${ }^{21}$ Conforme aponta Luis Regis Prado, no sistema francês, que inspirou o modelo adotado pelo Direito brasileiro, há uma "simbiose que legitima o empréstimo de criminalidade. A pessoa física personifica a jurídica (órgãos ou representantes), é onipresente, como sua consciência e cérebro". PRADO, Luiz Regis. Responsabilidade penal da pessoa jurídica: fundamentos e implicações, p. 124.

${ }^{22}$ Escreve o autor, textualmente: "Ao condicionar a responsabilidade penal à existência de uma decisão dos seus representantes legais ou contratuais da pessoa jurídica, impõe à persecução penal a mesma dificuldade antes observada, ou seja, de apurar o fato delitivo ligado a um ambiente inteiramente desfavorável, sujeito à complexidade e dissimulação dos processos decisórios da empresa e à pouca disposição de seus empregados testemunharem contra seus patrões" (p. 65).
}

Revista do Direitoda UNISC, Santa Cruz do Sul, v.1, n. 45, p. 61-88, jan. - abri. 2015. 
também responsabilizados por seus atos de gestão, "num sistema de dupla imputação".

ÉdisMilarée José Paulo da Costa Júnior (2002, p. 20-2)também se posicionam no sentido de que não é possível entender a questão da responsabilidade criminal do ente corporativo à luz dos "cânones tradicionais", havendo, portanto, necessidade de "reformulação do conceito". Por isso, escrevem que a "culpabilidade da pessoa jurídica não está adstrita à vontade, enquanto laço psicológico entre a conduta e o agente, ou à sua consciência da ilicitude, mas à reprovabilidade de sua conduta”. ${ }^{23}$

Dessa forma, a doutrina brasileira se posiciona no sentido de que o art.

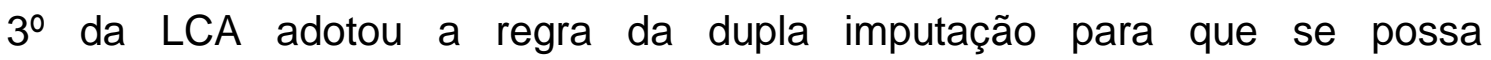
responsabilizar a pessoa jurídica pela prática de um crime ambiental. Em consequência, os seguintes requisitos são indispensáveis para se imputar responsabilidade penal ao ente corporativo: primeiro, que "a violação da norma ocorra por deliberação havida na esfera de poder legitimada a representar a pessoa jurídica e orientar seus caminhos". Tal deliberação pode ocorrer de forma voluntária (dolosa) como, também, de forma culposa.

O segundo requisito consiste na constatação da vinculação existente entre a conduta do executor material do fato lesivo e a deliberação institucional. Aqui, a lei estabelece a necessidade de um comportamento enquadrado no espaço das decisões, das deliberações, ou da política e das atividades assumidas pela empresa em face das normas de proteção de proteção ambiental. Sempre que a conduta individual for praticada no âmbito do poder decisório dos órgãos de deliberação ou de administração do ente corporativo ou se mostrar perfeitamente enquadrado ao seu modo de atuação em relação à questão ambiental, pode-se dizer que estamos diante de uma infração penal também imputável à pessoa jurídica.

\footnotetext{
${ }^{23}$ Para estes autores, a "doutrina tem vinculado a responsabilidade penal da pessoa jurídica à responsabilidade social", que permite construir um juízo de reprovação sobre a conduta da pessoa jurídica, não como um fato psicológico, mas como um comportamento institucional. Dessa forma, "O juízo realizado na responsabilidade social cumpre uma função própria: é um mecanismo de controle normativo social, que se exerce através da coação estatal, ao mesmo tempo em que resolve conflitos produzidos pela atividade de certas estruturas que entram em contradição com bens jurídicos fundamentais da comunidade. A punição atua como instrumento para corrigir a disfuncionalidade do sistema". In: COSTA JÚNIOR, Paulo José da; MILARÉ, Édis. Direito penal ambiental: comentários à Lei 9.605/98. Campinas: Millennium, 2002, p. 20-2.
}

Revista do Direitoda UNISC, Santa Cruz do Sul, v.1, n. 45, p. 61-88, jan. - abri. 2015. 
Como terceiro requisito legal está o elemento normativo de ter sido a infração cometida no interesse ou benefício do ente corporativo. Assim, para a lei brasileira, não basta a constatação apenas dos dois requisitos acima. É preciso, também, que a infração contra o ambiente seja praticada no interesse da pessoa jurídica para que esta venha a ser responsabilizada criminalmente. Se os dirigentes de uma empresa tomam uma decisão de agredir o ambiente, com o objetivo pessoal de auferir vantagens econômicas, em detrimento dos interesses da empresa, é evidente que esta não poderá ser acusada da prática de crime contra o ambiente, nos termos do art. $3^{\circ}$, da LCA.

Como acabamos de examinar, a doutrina brasileira convergiu para entender que, apesar da ambiguidade e da falta de clareza redacional do seu art. $3^{\circ}$, a LCA adotou a regra da dupla imputação material a fim de se estabelecer a responsabilidade da pessoa jurídica, no caso de crime contra 0 ambiente.

A seguir, examinaremos a hermenêutica judicial sobre a matéria, especialmente, os termos da decisão do STF que, ao contrário do que vinha sendo decidido, reconheceu a possibilidade de responsabilidade própria ou isolada do ente jurídico, como autor de crime ambiental.

\section{HERMENÊUTICA DO STJ E DO STF SOBRE O PRINCÍPIO DA RESPONSABILIDADE PENAL DA PESSOA JURÍDICA: Dupla Imputação ou Responsabilidade Própria da Pessoa Jurídica?}

\subsection{Ausência de Exame da Constitucionalidade do Art. $3^{\circ}$ pelo STF}

Cabe assinalar que, transcorridos mais de 25 anos, o STF ainda não enfrentou, expressamente, a questão de se saber se o § $3^{\circ}$, do art. 225, da CRFB/88, consagrou o princípio da responsabilidade penal da pessoa jurídica. Da mesma forma e, em consequência, a Suprema Corte ainda não decidiu, em última instância e, num processo hermenêutico conforme a Constituição, se a norma contida no art. $3^{\circ}$ da LCA é consentânea com a teoria do crime, da pena e com os princípios constitucionais penais que sustentam o ordenamento jurídico brasileiro. Em síntese, se a referida norma penal tem sua legitimidade

Revista do Direitoda UNISC, Santa Cruz do Sul, v.1, n. 45, p. 61-88, jan. - abri. 2015. 
assegurada em face do indispensável controle de constitucionalidade a que está sujeita toda lei penal, aprovada no contexto do Estado Democrático de Direito.

A questão tem relevância jurídica se for considerado que, desde o primeiro momento, estabeleceu-se uma polêmica acerca da validade da norma contida no art. $3^{\circ}$, da LCA. ${ }^{24}$ Embora a questão já se encontre praticamente consolidada no âmbito da jurisprudência do $S T J,{ }^{25}$ a verdade é que o STF ainda não se pronunciou, pela voz de seu Plenário, sobre a questão específica da constitucionalidade da norma que introduziu a responsabilidade criminal da pessoa jurídica no sistema penal brasileiro.

Esta questão poderia ter sido decidida ao tempo do julgamento do recurso extraordinário (RE 473.045-SC, j. em 15.10.2013), interposto pelo Ministério Público, contra decisão prolatada pela $2^{\text {a }}$ Câmara Criminal do TJSC, que manteve sentença de primeiro grau, negando a validade da norma contida no art. $3^{\circ}$, da LCA e, em consequência, rejeitou denúncia que responsabilizava a pessoa jurídica pela prática de crime ambiental. No entanto, os autos do processo dormiram nas gavetas e arquivos do STF, por mais de 12 anos sem julgamento do recurso e a ação penal foi julgada extinta pela prescrição penal, em 15.10.2013. ${ }^{26}$ A omissão da prestação jurisdicional pela Suprema Corte

\footnotetext{
${ }^{24}$ Com a promulgação da LCA, grande número de penalistas manifestaram-se contra a regra da responsabilidade criminal da pessoa jurídica. Para um estudo das razões sustentadas por essa corrente doutrinária, consultar, entre outros: SANTOS, Juarez Cirino dos. A Responsabilidade penal da pessoa jurídica. Direito e Sociedade - Publicação Semestral do Centro de Estudos e Aperfeiçoamento Funcional do Ministério Público do Estado do Paraná, vol. 2, n.1, p. 127-142, Curitiba, jan.-jun. 2001; GOMES, Luiz Flávio. Crime ambiental e responsabilidade penal de pessoa jurídica de direito público. Revista Magister de Direito Ambiental e Urbanístico - Publicação bimestral da Editora Magister Ltda., n. 17, Porto Alegre, Magister, abr./mai. 2008, p. 5-8.

${ }^{25}$ Diversas decisões do STJ reconheceram, expressa ou tacitamente, a validade do art. $3^{\circ}$, da LCA, que prescreve a responsabilidade criminal da pessoa jurídica. Ver, entre outros: RE 610114/RN, j. em 17.11.2005; RE 847.476/SC, j. em 08.04.2008);RE 989.089/SC, j. em 18.08.2009); RE 800.817/SC, j. em 04.02.2010; RHC 28.811/ SP, j. em 02.12.2010); Ag. Reg. no RE 898.302/PR, j. em 07.12.2010); RHC 24.125/SC, j. em 01.12.2011.

${ }^{26}$ Data do julgamento pelo ministro Gilmar Mendes, relator. Tratava-se de ação penal contra uma microempresa - Auto Posto de Lavagem Vale do Vinho Ltda. - e seu proprietário, pela suposta prática dos crimes de poluição por lançamento de resíduos sólidos, líquidos ou gasosos, ou detritos, óleos ou substâncias oleosas, em desacordo com as exigências estabelecidas em leis ou regulamentos. Com a rejeição da denúncia pelo juiz do processo, o Ministério Público interpôs recurso em sentido estrito ao TJSC. Com a confirmação da decisão de primeiro grau foi interposto o recurso extraordinário 473.045-SC, junto ao STF. Sobre a questão, consultar, ainda: SILVA, Ivan Luís Marques da. Responsabilidade penal das pessoas jurídicas: 21 anos da previsão constitucional e 11 anos da previsão legal: um balanço necessário.Revista dos Tribunais, ano 99, v. 891, p. 443-476, São Paulo, RT, jan.2010, p. 469.
}

Revista do Direitoda UNISC, Santa Cruz do Sul, v.1, n. 45, p. 61-88, jan. - abri. 2015. 
impediu que se tivesse a decisão de última instância para se colocar um ponto final na polêmica que ainda ronda os corredores forenses e os escaninhos do pensamento doutrinário sobre o verdadeiro sentido do direito contido no referido dispositivo constitucional e, por consequência, no art. $3^{\circ}$ da LCA.

Por isso, tem razão Paulo de Bessa Antunes (2007, p. 792), quando escreve que a responsabilidade penal da pessoa jurídica é uma questão que não pode ser considerada jurisprudencialmente pacífica, enquanto o STF não se manifestar de modo consistente sobre a matéria.

\subsection{Posição do STJ em Favor da Regra da Dupla Imputação}

Respaldando a posição defendida pela corrente doutrinária favorável à responsabilidade criminal da pessoa jurídica, o STJ admitiu que o $\S 3^{\circ}$, do art. 225, da CRFB/88 rompeu com o dogma da societas delinquere non potest. Pesquisa que fizemos, mostrou que essa Corte de Justiça Superior julgou mais de quatro dezenas de recursos, em cujos julgamentos foi admitida a validade da regra prescrita no art. $3^{\circ}$ da LCA e afirmado o entendimento de que a responsabilidade empresarial, somente pode ocorrer em coautoria com a pessoa física que tenha praticado o crime ambiental. Assim sendo, nessa Corte Superior, prevalece a hermenêutica de que a lei brasileira adotou a regra da dupla imputação material. ${ }^{27}$ Examinaremos apenas alguns desses acórdãos.

Em decisão que reflete o pensamento da Corte e que teve como relator o ministro Gilson Dipp, ficou decidido ser "inadmissível a imputação isolada da pessoa jurídica pela prática de crime ambiental". Para o Relator, a vontade criminosa da empresa confunde-se com a vontade de seus administradores, dirigentes ou funcionários que tenham agido por sua conta ou no seu interesse:

\footnotetext{
${ }^{27}$ A pesquisa na jurisprudência do site do STJ utilizou as expressões "crime ambiental e pessoa jurídica" e "responsabilidade penal da pessoa jurídica" e "crime ambiental". Foram identificados todos os julgados envolvendo a teoria da dupla imputação e a própria validade da regra que criou a RPPJ, prevista no art. $3^{\circ}$, da LCA. Embora não possa ser descartada a possibilidade de algum julgado não ter sido identificado, acreditamos que as principais decisões do STJ, sobre a teoria da dupla imputação - matéria objeto da presente pesquisa foram devidamente consultados, no endereço eletrônico do STJ é: <http://www.stj.jus.br/portal/site/STJ>.Acesso em: 15 de fev. de 2015. Ver, ainda: LEAL, Rodrigo José. Princípio constitucional do ambiente ecologicamente equilibrado e a responsabilidade penal da pessoa jurídica prevista na lei 9.605/98: controle penal efetivo $x$ controle penal simbólico do processo de degradação ambiental no Brasil. 2011, $543 \mathrm{f}$. Tese (Doutorado em Direito). Universidad de Alicante.
}

Revista do Direitoda UNISC, Santa Cruz do Sul, v.1, n. 45, p. 61-88, jan. - abri. 2015. 
"A pessoa jurídica só pode ser responsabilizada quando houver intervenção de uma pessoa física, que atua em nome e em benefício do ente moral". Concluiu seu voto, afirmando que "A ausência de identificação das pessoas físicas que, atuando em nome e proveito da pessoa jurídica, participaram do evento delituoso, inviabiliza o recebimento da exordial acusatória". ${ }^{28}$

Reiterando sua orientação jurisprudencial, o STJ deliberou que é perfeitamente admissível "a responsabilidade penal da pessoa jurídica em crimes ambientais desde que haja a imputação simultânea do ente moral e da pessoa física que atua em seu nome ou em seu benefício". Para a hermenêutica do STJ, não é compreensível "a responsabilização do ente moral dissociada da atuação de uma pessoa física, que age com elemento subjetivo próprio". Assim, tendo o delito sido imputado tão-somente à pessoa jurídica e, "não descrevendo a denúncia a participação de pessoa física que teria atuado em seu nome ou proveito, a ação penal fica completamente inviabilizada". ${ }^{29}$

Em outra decisão e, numa clara indicação de consolidar a hermenêutica favorável à exigência da regra da dupla imputação para que possa ser admitida a RPPJ em crimes ambientais, a Turma julgadora do recurso ratificou 0 entendimento de que se faz necessária a imputação simultânea do ente moral e da pessoa física que atua em seu nome ou em seu benefício. ${ }^{30}$ Assim, ficou decretado que deve ser excluída a ação penal contra a empresa, se seus dirigentes ou funcionários autores da conduta criminosa foram absolvidos ou excluídos da relação processual ${ }^{31}$

Finalmente, a adoção da teoria da dupla imputação ficou consolidada no julgamento do recurso ordinário em mandado de segurança, em que o STJ decidiu pela inépcia da denúncia formulada pelo Ministério Público do Estado

\footnotetext{
${ }^{28}$ RE 610114/RN, j. em 17.11. 2005. No mesmo sentido: Agr. na Reclamação 4.071/MG, j. em 26.05.2010. Outras decisões, nesse mesmo sentido: RHC 19119/MG, j. em 12.06.2006. Nesse sentido, foram proferidas as seguintes decisões, pelo STJ: RE $847.476 / \mathrm{SC}$, j. em 08.04.2008;RE 989.089/SC, j. em 18.08.2009; RE 800.817/SC, j. em 04.02.2010; RHC 28.811/ SP, j. em 02.12.2010; Ag. Reg. no RE 898.302/PR, j. em 07.12.2010; Embargos de Decl. no RE 865.864/PR, j. em 20.10.2011; RHC 24.125/SC, j. em 01.12.2011; RMS 20601/SP, j. em 29.06.2006; Agr. Reg. no MS 13533/SC, j. em 23.06.2008; RE 969160/RJ, j. em 06.08.2009.

${ }^{29}$ RMS 20601/SP, j. em 29.06.2006. No mesmo sentido: Agr. Reg. no MS 13533/SC, j. em 23.06.2008; RE 969160/RJ, j. em 06.08.2009.

${ }^{30}$ RE 889528/SC, j. em 17.04.2007; RHC 24055/RS, j. em 09.02.2010.

${ }^{31}$ RMS 16696/PR, j. em 09.02.2006.
}

Revista do Direitoda UNISC, Santa Cruz do Sul, v.1, n. 45, p. 61-88, jan. - abri. 2015. 
de São Paulo contra somente a Petrobras, isolada no polo passivo, depois da exclusão de dois dirigentes da empresa da ação penal. ${ }^{32}$

Infere-se dessa seleção de julgados colhidos no STJ, que a aplicação da teoria da dupla imputação, exigindo a responsabilização da pessoa jurídica, em concurso necessário com a pessoa física, resulta em enormes dificuldades ao controle penal ambiental, pois nem sempre é possível identificar o autor da infração penal ambiental dentro de um sistema complexo como ocorre na estrutura administrativa das grandes empresas, que venham a praticar graves crimes ambientais. A produção da prova do nexo causal entre a conduta da pessoa física ou do sócio efetivamente responsável pelo crime ambiental e o dano ambiental gerado pela pessoa jurídica é tarefa, em muitos casos, praticamente inviável.

Assim, a adoção da regra da dupla imputação material tem sido fator, no âmbito da prática judiciária, de um grande número de ações penais julgadas extintas, sem conhecimento do mérito, pela impossibilidade de identificação da pessoa física autora da conduta delitiva contra o ambiente.

\subsection{O STF e a Responsabilidade Criminal Própria da Pessoa} Jurídica

Apesar da posição assumida pela corrente doutrinária largamente majoritária, respaldada pela jurisprudência consolidada do STJ, ocorreu significativa mudança na hermenêutica da Suprema Corte, no que concerne à exigência da regra da dupla imputação para se responsabilizar o ente corporativo pela prática de uma infração penal contra o ambiente. Já havia precedente anterior do STF (RE 548181/PR, j. em 17.04.2009), admitindo a dupla imputação como requisito indispensável para se atribuir responsabilidade criminal à pessoa jurídica. No entanto, decisão mais recente, proferida pela Primeira Turma, afastou a exigência obrigatória da dupla imputação para admitir da responsabilidade isolada da empresa poluidora. ${ }^{33}$

\footnotetext{
${ }^{32}$ RMS 27.593/SP, j. em 04.09.2012. No mesmo sentido: RMS 37.293/SP, j. em 02.05.2013.

${ }^{33}$ RE 548181/PR, j. em 06.08.2013 e publicado somente em 30.10.2014), Min. Rel. Rosa Weber.
}

Revista do Direitoda UNISC, Santa Cruz do Sul, v.1, n. 45, p. 61-88, jan. - abri. 2015. 
Embora não seja uma decisão plenária, não se pode deixar de reconhecer a enorme repercussão que causou e continua causando no campo da jurisprudência dos tribunais estaduais e, principalmente, do STJ sobre a matéria objeto deste estudo. Agora, permanece a expectativa em face de novos julgamentos que possam consolidar a posição do STF a respeito desta relevante, mas indefinida questão.

Em síntese, cabe esclarecer que o recurso julgado pela Suprema Corte teve origem em ação penal proposta contra a Petrobras, seu presidente e mais um dirigente da empresa. No STJ, após demorada e acirrada batalha recursal, os dois dirigentes empresariais foram excluídos da ação penal e esta declarada extinta, decisão que foi acatada pelo STF. ${ }^{34}$

Dessa forma, não se discutiu no julgamento do Habeas Corpus em tela a capacidade penal da pessoa jurídica, mas apenas a questão da imputabilidade ao presidente da empresa estatal por um fato ocorrido de forma acidental, longe do olhar direto da administração superior e, evidentemente, sem que tivesse ocorrido qualquer tipo de deliberação por parte do comando administrativo da estatal petroleira.

Com a negativa de seguimento ao recurso extraordinário ${ }^{35}$, o MPF interpôs agravo regimental. ${ }^{36}$ Ao votar pelo seu provimento a Min. Rel. Rosa Weber admitiu a presença de questão constitucional maior para que, em posterior julgamento em recurso extraordinário, fosse examinada pela primeira turma do STF a questão de se condicionar a responsabilização penal da pessoa jurídica a uma identificação e manutenção, na relação jurídicoprocessual, da pessoa física ou natural, que segundo a Relatora se trata de uma exigência que parece não existir no art.225, $\S 3^{\circ}$, da Constituição Federal.

No julgamento do recurso extraordinário, cujo acórdão só foi publicado em 30.10.2014, a relatora Rosa Weber registrou o argumento do MPF de que a decisão do STJ, de condicionar a persecução penal da pessoa jurídica à da pessoa física responsável individualmente pelos fatos, representa negativa de

\footnotetext{
${ }^{34} \mathrm{Na}$ Corte Suprema, o Relator do processo, Min. Gilmar Mendes, afastou a responsabilidade penal do presidente da Petrobrás, por entender que não havia nexo causal entre a conduta de ser presidente da empresa e o vazamento de um oleoduto a esta pertencente. Para o relator, "entre a Presidência da Petrobrás e um tubo de óleo, há inúmeras instâncias gerenciais e de operação em campo". (HC 83554-6/PR, j. em 16.08.2005).

${ }^{35}$ RE 548181/PR, j. em 17.04.2009.

${ }^{36}$ Ag. Reg. RE 548181/PR, j. em 14.05.2013.
}

Revista do Direitoda UNISC, Santa Cruz do Sul, v.1, n. 45, p. 61-88, jan. - abri. 2015. 
vigência ao art. 225, $\S 3^{\circ}$, da Constituição Federal, que prevê a responsabilidade penal da pessoa jurídica por crime ambiental sem este condicionamento. Para o MPF este entendimento

geraria impacto na eficácia da responsabilização penal da pessoa jurídica, já que não raras vezes, por questões probatórias, seria impossível identificar, no âmbito da empresa, a pessoa física especificamente responsável pelo delito ambiental.

Em extenso voto, Rosa Weber reconheceu os argumentos do MPF e aduziu que seria possível concordar com a necessidade de se condicionar a persecução penal da pessoa jurídica à persecução da pessoa física especificamente responsável pelo delito. No entanto, para ela, deve preponderar "o argumento do Ministério Público, de que tal condicionamento pode impactar a eficácia do princípio constitucional da responsabilidade penal da pessoa jurídica em crime contra o meio ambiente, se mostra impregnado de razoabilidade".

Em seu voto, a relatora diz, ainda, que a teoria da dupla imputação, adotada pelo STJ, "condicionaria a interpretação e aplicação da norma constitucional do $\S 3^{\circ}$ do art. 225 da Carta Política a uma concreta identificação e imputação também da pessoa física". Tal interpretação, a seu ver, estaria restringindo sobremaneira sua eficácia e contrariando a intenção expressa do constituinte originário. Estaria, também, restringindo o alcance das sanções penais e da tutela do bem jurídico ambiental.

Por fim, Rosa Weber ressaltou que 0 § $3^{\circ}$ do art. 225 da Carta Política objetiva proteger um verdadeiro direito fundamental de terceira geração, de titularidade difusa, consistindo em comando ao legislador para a instituição de mecanismos de responsabilização civil, administrativa e penal de infratores da legislação ambiental, pessoas físicas ou jurídicas.

Desse modo, a Primeira Turma do STF, deu provimento, em parte, ao recurso para, reconhecida a possibilidade de a denúncia por crime ambiental contra a pessoa jurídica não abranger, necessariamente, a atribuição criminal do fato também à pessoa física, determinando o regular processamento da ação penal contra a Petrobrás. ${ }^{37}$

37 Registre-se que no RE 628582/RS-AgR, j. em 06.09.2011 o Ministro Dias Toffoli se manifestou no sentido de que a responsabilidade penal isolada da pessoa jurídica não viola o $\S$

Revista do Direitoda UNISC, Santa Cruz do Sul, v.1, n. 45, p. 61-88, jan. - abri. 2015. 
O que parece emergir da decisão do STF é que a teoria da dupla imputação, adotada pelo STJ, não tem permitido um controle penal eficaz para reprimir eventuais condutas criminosas cometidas pela pessoa jurídica contra o ambiente. Ao adotar a teoria da dupla imputação e justificar a incapacidade de conduta do ente moral, o STJ optou por uma fórmula que condiciona, necessariamente, a imputação penal da pessoa jurídica à da pessoa física, condicionamento que, na prática, tem criado entraves e, em muitos casos, impedido a efetiva aplicação da lei penal de proteção ao ambiente.

Por isso, a nova posição da jurisprudência do STF, no sentido de admitir a responsabilidade penal isolada da pessoa jurídica, parece ter sido uma resposta a esses entraves processuais que, desde o início da vigência do art. $3^{\circ}$ da Lei 9.605/98, tem dificultado ou impossibilitado a punição da pessoa jurídica por crime ambiental. $\mathrm{Na}$ verdade, a rígida aplicação dos requisitos impostos pela regra da dupla imputação tem sido responsável pelo grande número de decisões extintivas da punibilidade, em ações penais contra empresas causadoras de danos ambientais. Este fato, a nosso ver, tem sido responsável, em grande parte, pela ineficácia e falta de efetividade da proposta punitiva de se responsabilizar a empresa criminosa contra o ambiente. Com isso, a LCA, com suas normas formais de prevenção e repressão às condutas empresariais lesivas ao ambiente, parece ter restado apenas uma função meramente simbólica como instrumento de controle penal do bem jurídico ambiental.

\section{CONSIDERAÇÕES FINAIS}

A Constituição da República Federativa do Brasil, com seu texto comprometido com a construção de um Estado Democrático de Direito e de bem estar social, fundado nos valores da dignidade da pessoa humana, da cidadania e do pluralismo político, abriu importante espaço normativo para firmar o indispensável compromisso com o controle e a preservação do ambiente saudável e equilibrado. Considerada de "Carta Verde", a CRFB

3o do artigo 225 da CRFB/88. Já no RE 548181/PR o Min. Marco Aurélio manifestou posição divergente e concluiu, ao votar que não houve violação do preceito do artigo 225 da Constituição Federal, diante das balizas objetivas e subjetivas da persecução criminal.

Revista do Direitoda UNISC, Santa Cruz do Sul, v.1, n. 45, p. 61-88, jan. - abri. 2015. 
constitui um importante instrumento políticojurídico formal na história do povo brasileiro.

A doutrina tem considerado que o texto do $\S 3^{\circ}$, do art. 225, da CRFB, que se refere à responsabilidade criminal da pessoa jurídica, tem redação ambígua e isto gerou sérias divergências entre os autores que estudaram a matéria. Mas, prevalece entre os autores e, principalmente, na jurisprudência, o entendimento de que o referido dispositivo constitucional rompeu com a regra da societas non delinquerepotest.

Apesar da forte resistência de parte da doutrina, a validade formal do art. $3^{\circ}$, da Lei 9.605/98, decorre do próprio texto constitucional (art. 225, § 3º), cujo comando normativo faz referência à capacidade penal dos entes coletivos. Se a Carta Magna sinaliza para a hipótese de se imputar capacidade penal à pessoa jurídica em matéria de crime ambiental, não se pode falar de inconstitucionalidade da norma ordinária, que apenas cumpriu o referido mandamento constitucional e que foi aprovada segundo o devido processo legislativo.

A redação dada à norma contida no seu art. 3ํ, da LCA, peca por falta de clareza e objetividade. Mas, numa interpretação segundo os termos da lei, é possível dizer que o critério ali adotado corresponde ao modelo de responsabilidade penal por atribuição ou de identificação de responsabilidade. $\mathrm{Na}$ doutrina brasileira, a corrente largamente majoritária defende esta posição para afirmar que o modelo aqui praticado, por força do art. 3ํ da LCA, é o da dupla imputação ou dupla incriminação.

Este é o entendimento adotado pelo STJ, que consolidou sua jurisprudência no sentido de não admitir que a pessoa jurídica possa atuar com responsabilidade penal própria, no cometimento de uma infração penal ambiental. É o reconhecimento da teoria da dupla imputação.

No entanto, recentemente ocorreu significativa mudança na hermenêutica da Suprema Corte, que rechaçou a exigência obrigatória da regra da dupla imputação para se responsabilizar o ente corporativo pela prática de uma infração penal contra o ambiente. Para a relatora do acórdão, a exigência da dupla imputação, estaria restringindo sobremaneira a eficácia da norma constitucional (art. 225, $\S 3^{\circ}$, da CRFB) e contrariando a intenção 
expressa do constituinte originário, além de restringir, também, o alcance das sanções penais e da tutela do bem jurídico ambiental.

Finalmente, a pesquisa realizada mostrou que o art. $3^{\circ}$ da LCA não está cumprindo - com a necessária e desejada eficácia - sua relevante função de prevenção e de repressão aos atentados ambientais mais severos e devastadores. A maioria das ações penais acabou extinta sem julgamento do mérito, enquanto que o número de efetivas condenações restringiu-se a uma cifra verdadeiramente insignificante.

A efetiva eficácia da norma constitucional ( $3^{\circ}$. do art. 225 da CRFB/88) e infraconstitucional (art.3‥ da Lei 9.605/98) será sempre um desafio e para tanto será preciso contar com a atuação firme dos órgãos de controle formal do Estado e, principalmente, a participação coletiva de todos os cidadãos. Afinal, tal participação foi erigida em princípio constitucional de defesa do ambiente (art. 225, caput). Com isso, será possível avançar no legítimo processo de prevenção e de repressão à criminalidade ambiental cometida pelas empresas e evitar que a norma penal contida no art. $3^{\circ}$, da Lei dos Crimes Ambientais, apresente um efeito meramente simbólico, como ocorre em relação a tantas outras normas de Direito Penal.

\section{REFERÊNCIAS}

AMORIM, Manoel Carpena. Responsabilidade penal da pessoa jurídica.

Revista da Escola da Magistratura do Estado do Rio de Janeiro, p. 23-37, v. 3, nำ 10, 2000.

ANTUNES, Paulo de Bessa. Direito ambiental. 10a․ ed., rev., ampl. e atual. Rio de Janeiro: Lumen Juris, 2007.

ARAÚJO JUNIOR, João Marcello de. Societas delinquerepotest - revisão da legislação comparada e estado atual da doutrina. p. 72-94. In: GOMES, Luiz Flávio (Coord.). Responsabilidade penal da pessoa jurídica e medidas provisórias e direito penal. Coleção temas atuais de direito criminal vol. 2. São Paulo: RT, 1999.

COSTA JÚNIOR, Paulo José da; MILARÉ, Édis. Direito penal ambiental: comentários à Lei 9.605/98. Campinas: Millennium, 2002.

GARCEZ, José Maria Rossani. Responsabilidade objetiva ("strict liability"), negligência ("negligence") e negligência dolosa ("gross negligence"). Jus

Revista do Direitoda UNISC, Santa Cruz do Sul, v.1, n. 45, p. 61-88, jan. - abri. 2015. 
Navigandi, Teresina, ano 12, n. 1617, 5 dez. 2007. Disponível em: <http://jus.com.br/artigos/10732>. Acesso em: 22 fev. 2015.

GARCÍA ARÁN, Mercedes. Algunas consideraciones sobre la responsabilidad penal de las personas jurídicas. p.325-333. In: CEREZO MIR, José et al (Ed.). El nuevo código penal: presupuestos y fundamentos: libro homenaje al professor doctor Don Ángel Torío López. Granada: Comares, 1999.

GOMES, Luiz Flávio. Crime ambiental e responsabilidade penal de pessoa jurídica de direito público. Revista Magister de Direito Ambiental e Urbanístico - Publicação bimestral da Editora Magister Ltda., n. 17, Porto Alegre, Magister, abr./mai. 2008.

GÓMEZ-JARA DÍEZ, Carlos. Corporate criminal liability: algunas cuestiones sobre la responsabilidad penal corporativa en los EE.UU. p. 195-231.In: GARCÍA CAVERO, Percy (Coord.). La responsabilidad penal de las personas jurídicas, órganos y representantes. ${ }^{1}$. reimp.Mendoza: Cuyo, Nov. 2005.

LEAL, Rodrigo José. Princípio constitucional do ambiente ecologicamente equilibrado e a responsabilidade penal da pessoa jurídica prevista na lei 9.605/98: controle penal efetivo $x$ controle penal simbólico do processo de degradação ambiental no Brasil. 2011, 543 f. Tese (Doutorado em Direito). Universidad de Alicante.

LUISI, Luis. Notas sobre a responsabilidade penal das pessoas jurídicas. p. 2742. In: PRADO, Luiz Regis; DOTTI, René Ariel. (Coords.). Responsabilidade penal da pessoa jurídica: em defesa do princípio da imputação penal subjetiva. ${ }^{\mathrm{a}}$. ed. rev., atual. e ampl. São Paulo: RT, 2010.

MEIRA, Bruno TanusJob e. A responsabilidade penal das pessoas jurídicas como conseqüência da tutela penal ambiental: considerações à luz do ordenamento jurídico espanhol.Revista IOB de Direito Penal e Processual Penal, ano VIII, n. 46, p. 51-80, São Paulo, IOB, out-nov. 2004.

MILARÉ, Édis. Direito do ambiente: doutrina, jurisprudência, glossário. 4⿳a ${ }^{\mathrm{a}}$. ed. rev., atual. e ampl. São Paulo: RT, 2005.

MORAES, Alexandre de. Direito constitucional. 23ㄹ. ed., 2ª reimpr. São Paulo: Atlas, 2008.

NIETO MARTÍN, Adán. La responsabilidad penal de las personas jurídicas: un modelo legislativo. Madrid: Iustel, 2008.

PRADEL, Jean. A responsabilidade penal das pessoas jurídicas no direito francês: ensaio de resposta a algumas questões chave. Trad. de Berenice Maria Giannella. Revista Brasileira de Ciências Criminais - Publicação oficial do Instituto Brasileiro de Ciências Criminais, ano 6, n. 24, p. 51-63, São Paulo, RT, out.-dez. 1998.

Revista do Direitoda UNISC, Santa Cruz do Sul, v.1, n. 45, p. 61-88, jan. - abri. 2015. 
PRADO, Alessandra Rapassi M. Proteção penal do meio ambiente: fundamentos. São Paulo: Atlas, 2000.

PRADO, Luiz Regis. Crime ambiental: responsabilidade penal da pessoa jurídica? Boletim IBCCrim - Publicação oficial do Instituto Brasileiro de Ciências Criminais, ed. Especial, n. 65, p. 2-3, São Paulo, abril/1998.

Direito penal do ambiente: meio ambiente, patrimônio cultural, ordenação do território e biossegurança (com a análise da Lei 11.105/2005). São Paulo: RT, 2005.

Responsabilidade penal da pessoa jurídica:

fundamentos e implicações. p.101-135. In: PRADO, Luiz Regis (Coord.). Responsabilidade penal da pessoa jurídica: em defesa do princípio da imputação penal subjetiva. São Paulo: RT, 2001.

REALE JÚNIOR, Miguel. A Lei de crimes ambientais. Revista Forense, ano 95, v. 345, p. 121-127, Rio de Janeiro, Forense, jan./fev./mar. 1999.

RIBAS, Lídia Maria Lopes Rodrigues. Responsabilidade penal da pessoa jurídica. Revista de Direito Ambiental-Publicação oficial do Instituto "O Direito por um Planeta Verde”, ano 7, n. 25, p. 95-107, São Paulo, RT, jan.-mar. 2002.

RIBEIRO, Lúcio Ronaldo Pereira. Da responsabilidade penal da pessoa jurídica e a nova lei dos crimes ambientais.Revista de Direito Ambiental - Publicação oficial do Instituto "O Direito por um Planeta Verde", ano 3, n. 12, p. 85-93, São Paulo, RT, out.-dez. 1998.

ROSAL, Bernardo del. La delimitación típica de losllamadoshechos de conexiónenelnuevo artículo 31 bis, n. 1, del Código Penal. págs. 41-94, Cuadernos de Política Criminal, №. 103, 2011.

ROTHENBURG, Walter Claudius.Responsabilidade penal da pessoa jurídica na nova lei de infrações ambientais. Revista de Direito Ambiental Publicação oficial do Instituto "O Direito por um Planeta Verde", ano 3, n.9, p. 59-66, São Paulo, RT, jan.-mar. 1998.

SALLES, Carlos Alberto de. Responsabilidade penal da pessoa jurídica e a proteção ao meio ambiente: finalidade e aplicação. Revista Brasileira de Ciências Criminais - Publicação oficial do Instituto Brasileiro de Ciências Criminais, ano 9, n. 36, p. 51-67, São Paulo, RT, out.-dez. 2001.

SANTOS, Juarez Cirino dos. A Responsabilidade penal da pessoa jurídica. Direito e Sociedade - Publicação Semestral do Centro de Estudos e Aperfeiçoamento Funcional do Ministério Público do Estado do Paraná, vol. 2, n.1, p. 127-142, Curitiba, jan.-jun. 2001.

SILVA, Fernando Quadros da. Responsabilidade penal da pessoa jurídica: a Lei 9.605, de 13.02.1998 e os princípios constitucionais penais.Revista de

Revista do Direitoda UNISC, Santa Cruz do Sul, v.1, n. 45, p. 61-88, jan. - abri. 2015. 
Direito Ambiental - Publicação oficial do Instituto "O Direito por um Planeta Verde", ano 5, n.18, p. 163-197, São Paulo, RT, abr.-jun. 2000.

SILVA, José Afonso da. Curso de direito constitucional positivo. 25ạ. ed., rev. e atual. São Paulo: Malheiros, 2005.

SILVA, Luciano Nascimento. O direito penal econômico como direito penal da empresa (o dualismo jurídico-criminal societas delinquere non potestvs societas delinquerepotest).p. 241-310. In: SILVA, Luciano Nascimento (Coord.).

Estudos jurídicos criminais. Curitiba: Juruá. 2008.

SILVA SÁNCHEZ, Jesús-María. La responsabilidad penal de las personas jurídicas y las consecuencias accesorias del artículo 129 del código penal español. p. 101 e 152.In: GARCÍA CAVERO, Percy (Coord.). La responsabilidad penal de las personas jurídicas, órganos y representantes. $1^{\mathrm{a}}$. reimp.Mendoza: Cuyo, Nov. 2005.

SOUZA, José Carlos Rodrigues de. Responsabilidade penal da pessoa jurídica e sua justificativa social. Revista de Direito Ambiental - Publicação oficial do Instituto "O Direito por um Planeta Verde", ano 3, n.9, p. 137-144, São Paulo, RT, jan.-mar. 1998.

TIEDEMANN, Klaus. Responsabilidad penal de personas jurídicas y empresas en el derecho comparado. p.25-45. In: Responsabilidade penal da pessoa jurídica e medidas provisórias e direito penal. Coleção temas atuais de direito criminal vol. 2. São Paulo: RT, 1999.

Revista do Direitoda UNISC, Santa Cruz do Sul, v.1, n. 45, p. 61-88, jan. - abri. 2015. 